\title{
PEMBERDAYAAN EKONOMI MASYARAKAT PESISIR MELALUI PENGOLAHAN RUMPUT LAUT
}

\author{
I Wayan Sujana ${ }^{1}$, Waode Al Zarliani ${ }^{2}$, Hastuti ${ }^{3}$ \\ ${ }^{1}$ Program Studi Akuntansi Universitas Muhammadiyah Buton \\ ${ }^{2}$ Program Studi Agribisnis Universitas Muhammadiyah Buton \\ ${ }^{3}$ Program Studi Manajemen Universitas Muhammadiyah Buton \\ e-mail: sujanawayan1@gmail.com
}

\begin{abstract}
Abstrak
Tujuan yang ingin dicapai dengan kegiatan pengabdian pada masyarakat ini melalui seminar adalah masyarakat pesisir khususnya generasi muda memahami bagaimana memelihara dan mengolah rumput laut menjadi produk bernilai ekonomis tinggi, serta masyarakat pesisir mempunyai kreatifitas untuk menghasilkan inovasi produk baru dari bahan pokok rumput laut. Salah satu produk inovasi dari potensi rumput laut yang dipraktekkan bersama dengan masyarakat yakni Es Sarang Rumput Laut. Generasi muda masyarakat pesisir yang merupakan penerus harus ikut serta dalam pengelolaan, pemanfaatan serta penciptaaan produk baru berbasis potensi lokal seperti rumput laut. Untuk mendukung hal tersebut maka kegiatan seperti ini hendaklah selalu dilakukan baik itu dalam bentuk seminar, pelatihan, penyuluhan, sosialisasi dan sebagainya, agar masyarakat mendapatkan penyegaran secara terus menerus.
\end{abstract}

\section{Kata Kunci: Pemberdayaan Ekonomi, Pesisir, Rumput Laut}

\section{A. Pendahuluan}

Kabupaten Buton Tengah sebagai daerah otonomi baru pemekaran dari kabupaten Buton yang terbentuk berdasarkan Undang-Undang Nomor 15 Tahun 2014 terletak di jazirah tenggara pulau Sulawesi yang sebagian wilayahnya berada di Pulau Muna sebagian lainnya kepulauan Talaga dan bila ditinjau dari peta Provinsi Sulawesi Tenggara, secara geografis terletak dibagian selatan garis katulistiwa, memanjang dari utara ke selatan diantara $4,96^{0}$ $6,25^{0}$ Lintang Selatan dan membentang dari barat ke timur diantara $122,00^{0}-123,34^{0}$ Bujur Timur, meliputi sebagian Pulau muna dan Buton Tengah. (BPS Kabupaten Buton, 2018)

Kabupaten Buton Tengah di sebelah utara berbatasan dengan Kabupaten Muna, di sebelah selatan berbatasan dengan Laut Flores, di sebelah timur berbatasan dengan Kota Baubau dan sebelah barat berbatasan dengan Kabupaten Bombana.

Desa Langkomu terletak di Kecamatan Mawasangka Tengah. Batas Wilayah Kecamatan Mawasangka Tengah yaitu sebelah utara berbatasan dengan Kecamatan 
Mawasangka dan Kecamatan Lakudo, sebelah selatan berbatasan dengan Kecamatan Mawasangka Timur, sebelah timur berbatasan dengan Kecamatan Lakudo dan sebelah barat berbatasan dengan Kecamatan Mawasangka. Luas Wilayah Desa Langkomu adalah $48 \mathrm{Km}^{2}$ atau 24,68\% dari luas wilayah Kecamatan Mawasangka Tengah.

Upaya Pemerintahan Daerah Kabupaten Buton Tengah dalam meletakkan sendisendi kehidupan masyarakat desa yang berkecukupan material dan spiritual serta makin adil dan merata guna terwujudnya desa pancasila. Kriteria dan kategori pembangunan desa dibedakan menjadi desa swadaya, desa swakarsa dan desa swasembada.

Dalam upaya membangun masyarakat pesisir agar potensi pembangunan masyarakat dapat dikelola dengan baik, maka salah satu strategi yang harus dilakukan adalah dengan membangun dan memperkuat kelembagaan sosial yang dimiliki atau yang ada pada masyarakat dan mengembangkan kualitas Sumber Daya Manusia (SDM) dengan jalan meningkatkan wawasan pembangunan dan keterampilan ekonomi masyarakat.

Wilayah pesisir merupakan wilayah yang penting apabila ditinjau dari berbagai sudut pandang perencanaan dan pengelolaan. Transisi antara daratan dan lautan di wilayah pesisir telah membentuk ekosistem yang beragam dan sangat produktif serta memberikan nilai ekonomi yang luar biasa terhadap manusia.(Muh. Askal Basir, Hardin, 2018). Wilayah pesisir merupakan kawasan sumber daya potensial di Indonesia yang harus diberdayakan oleh pemerintah. Pemberdayaan adalah menyediakan sumber daya, kesempatan, pengetahuan dan keterampilan dalam rangka meningkatkan kemampuan warga untuk menentukan masa depannya sendiri dan berpartisipasi dalam kehidupan masyarakat (Imam, 2016). Desa Langkomu merupakan salah satu wilayah pesisir di Kabupaten Buton Tengah, yang sebagian masyarakatnya mempunyai mata pencaharian sebagai petani rumput laut.

Masyarakat pesisir adalah orang yang tinggal di daerah pesisir dan sumber kehidupan ekonominya bergantung secara langsung pada pemanfaatan sumber daya laut dan pesisir. Dalam pembangunan di wilayah pesisir, salah satu kegiatan pengembangan kegiatan ekonomi yang sedang digalakkan pemerintah adalah pemgembangan budidaya rumput laut. Pengembangan budidaya rumput laut merupakan salah satu upaya pemberdayaan masyarakat pesisir yang mempunyai keunggulan dalam hal: (1) Produk yang dihasilkan mempunyai kegunaan yang beragam, (2) tersedianya lahan untuk budidaya yang cukup luas serta (3) mudahnya teknologi yang diperlukan (Departemen Kelautan dan Perikanan). 
Tim Pengusul Pengabdian melihat potensi desa berupa rumput laut pemanfaatannya masih sebatas produk mentah yang tentu saja nilai ekonomisnya masih kurang. Kami menawarkan contoh produk yang bisa dikembangkan dengan bahan dasar rumput laut seperti Es Sarang Rumput Laut, Keripik Rumput Laut, Kerupuk Rumput Laut, Brownies Rumput Laut dan sebagainya yang tentu saja nilai ekonominya menjadi lebih tinggi.

\section{B. Masalah}

Berdasarkan latar belakang yang telah diuraikan diatas pengabdi merumuskan masalah sebagai berikut:

1. Bagaimana menumbuhkan kesadaran masyarakat khususnya generasi muda dalam pemeliharaan dan pengolahan rumput laut menjadi produk yang bernilai ekonomis lebih dari produk yang dihasilkan?

2. Bagaimana mengembangkan pengetahuan masyarakat pesisir untuk menghasilkan inovasi produk atau usaha lain berbasis rumput laut?

\section{Metode Pelaksanaan}

Objek yang menjadi sasaran kegiatan pengabdian pada masyarakat ini adalah pemerintah desa dan masyarakat pesisir. Capaian yang diharapkan dalam kegiatan pengabdian pada masyarakat ini adalah 1) Masyarakat pesisir khususnya generasi muda di wilayah pesisir memahami bagaimana memelihara dan mengolah rumput laut menjadi produk bernilai ekonomis lebih tinggi 2) Masyarakat pesisir mempunyai kreatifitas untuk menghasilkan inovasi produk baru dari bahan pokok rumput laut.

Kegiatan ini akan dilaksanakan di Desa Langkomu Kecamatan Mawasangka Tengah Kabupaten Buton Tengah selama 1 bulan dengan tahap sebagai berikut:

1. Survey dan konfirmasi dengan pemerintah desa tentang kondisi lokasi pengabdian

2. Rapat dengan Tim Pelaksana untuk membahas agenda kegiatan pengabdian

3. Menghubungi kembali pihak kepala desa untuk mengajukan permohonan pelaksanaan pengabdian pada masyarakat di Desa Langkomu.

4. Mempersiapkan alat dan bahan-bahan seminar

5. Pelaksanaan kegiatan pengabdian berupa seminar di desa

Metode pelaksanaan kegiatan ini yakni ceramah dan diskusi (LODM Mustari, Antasalam Ajo, Azelia Monica A, 2019), dengan perangkat desa dan masyarakat pesisir 
bagaimana mengolah rumput laut menjadi produk baru yang bernilai ekonomis lebih tinggi, tidak hanya dijual dalam bentuk rumput laut basah atau kering.

\section{Pembahasan}

Kegiatan seminar ini diselenggarakan di Desa Langkomu Kecamatan Mawasangka tengah Kabupaten Buton Tengah pada tanggal 31 Maret 2020 mulai jam 09.00 sampai selesai. Hal ini adalah wujud pengabdian kami kepada masyarakat yang merupakan salah satu bagian dari Catur Dharma Perguruan Tinggi.

Kegiatan ini dihadiri oleh Kepala Desa Langkomu, sekretaris desa, masyakarat pesisir serta para generasi muda wilayah pesisir Desa Langkomu Kecamatan Mawasangka Tengah Kabupaten Buton Tengah. Seminar ini diawali dengan pemaparan materi tentang pemberdayaan masyarakat, bagaimana menumbuhkan jiwa wirausaha masyarakat pesisir, bagaimana menciptakan inovasi terhadap produk agar mempunyai nilai lebih untuk produk yang dihasilkan.

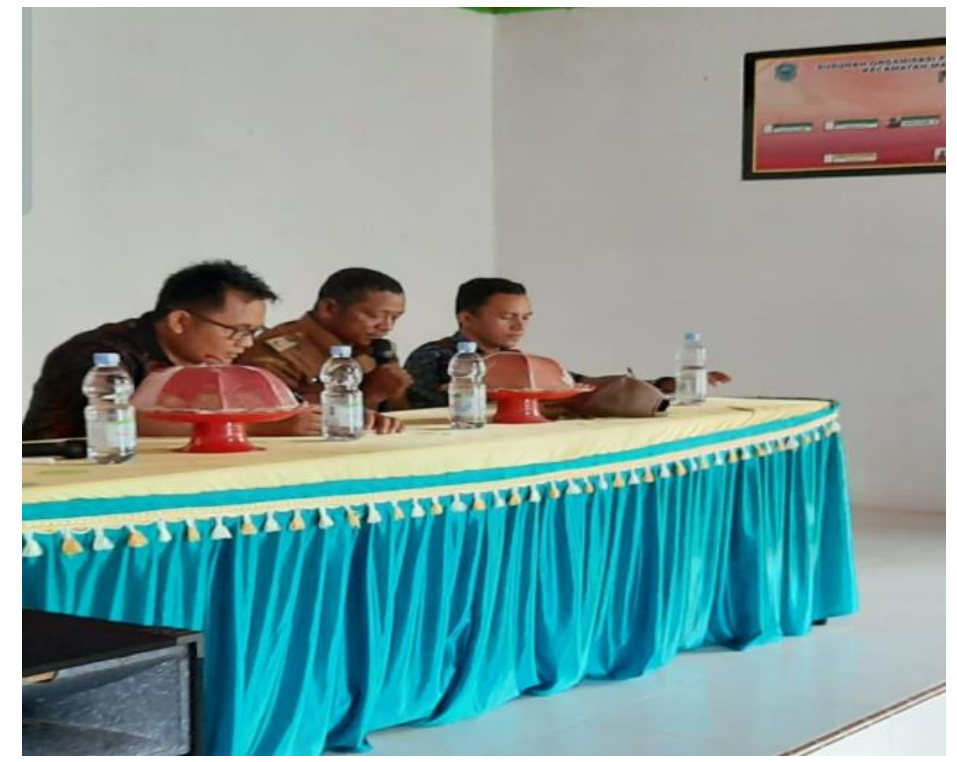

Gambar 1. Sambutan Kepala Desa Langkomu 

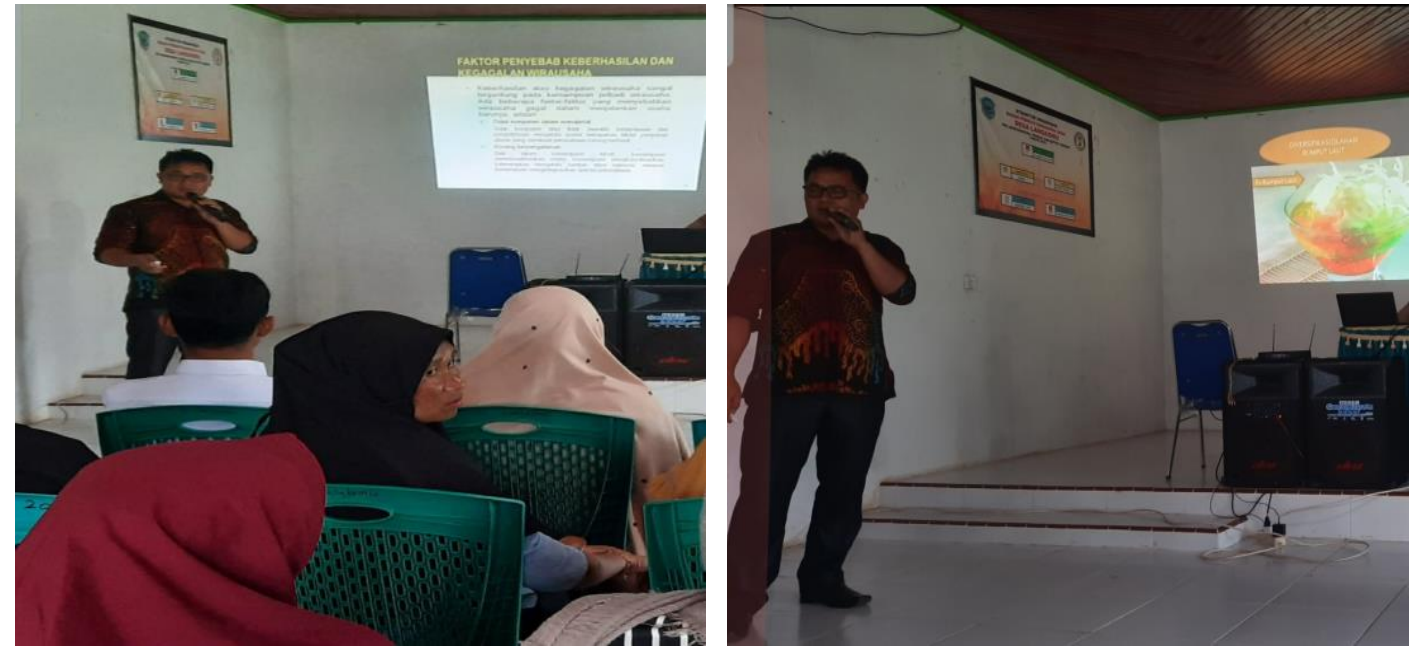

Gambar 2. Pemaparan Materi

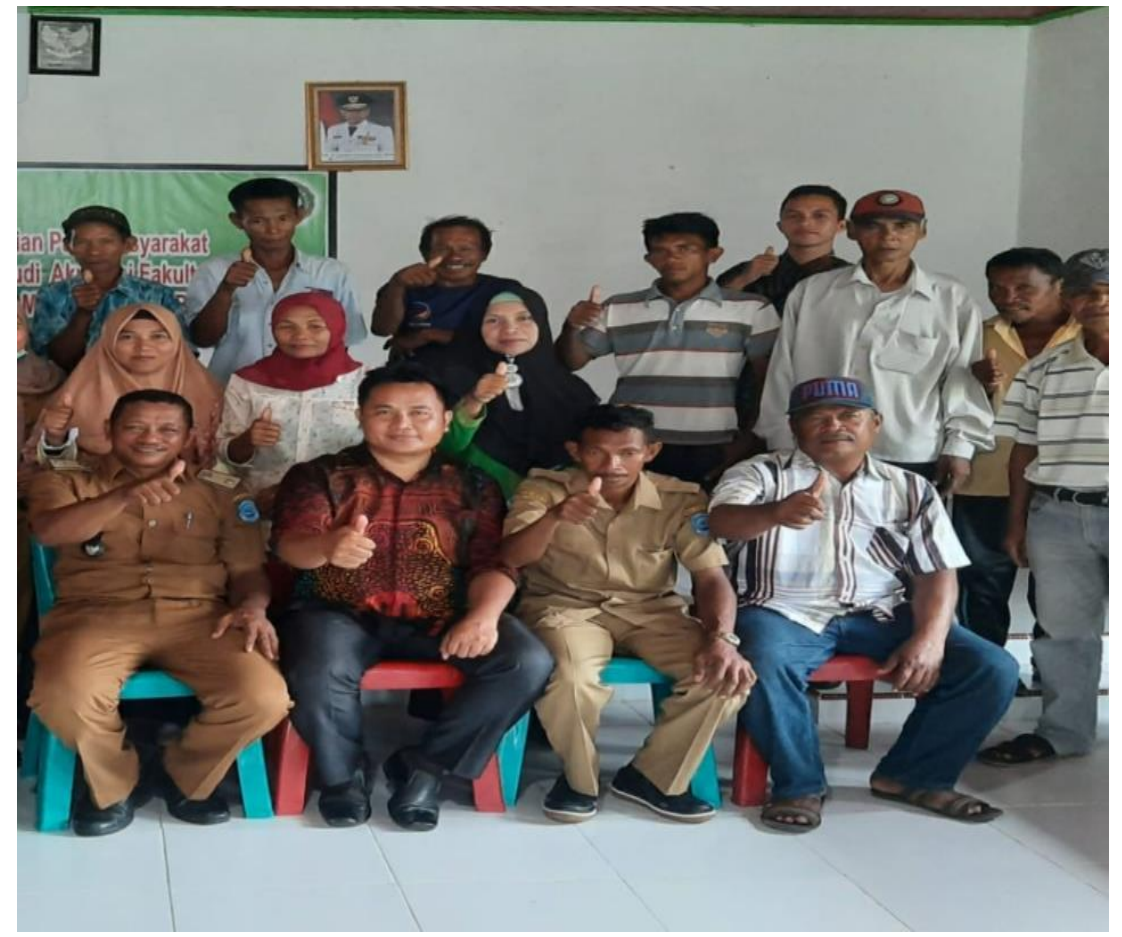

Gambar 3. Berpose dengan Pihak Pemerintah Desa dan Masyarakat

Tujuan kegiatan ini seperti yang telah diuraikan sebelumnya bahwa kami ingin memberikan pengetahuan melalui salah satu contoh produk bernilai ekonomis tinggi berbahan dasar rumput laut, dan yang menjadi hasil dari praktek pembuatan produk ini adalah Es Sarang Rumput Laut. 
Bahan: Kelapa Muda di Kerok

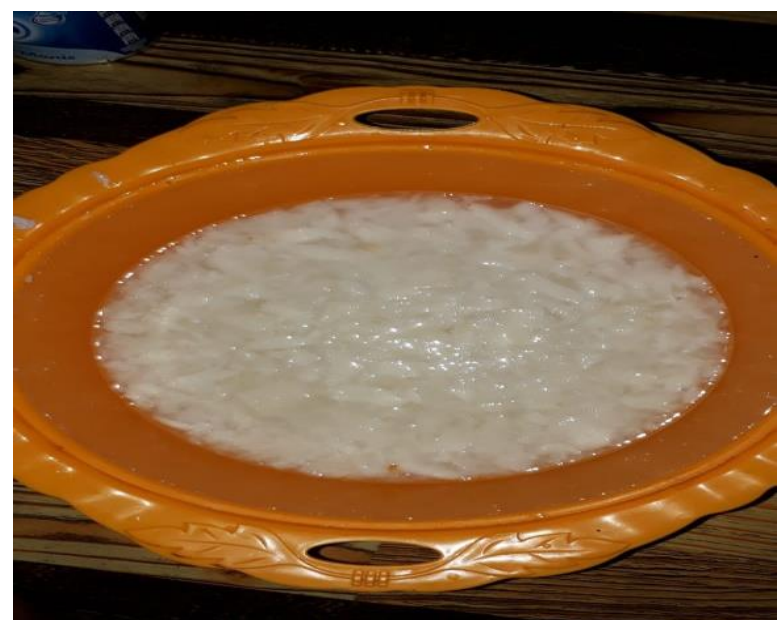

Gambar 4. Rumput Laut Kering di Masak dan Dicampur Gula Pasir

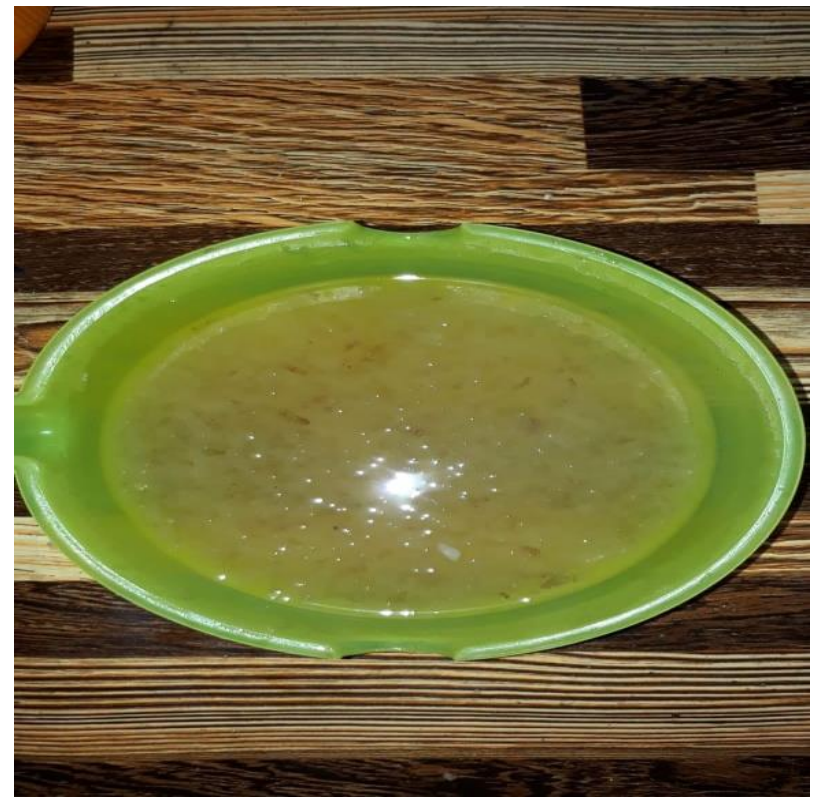

Gambar 5. Proses Pencampuran Bahan-Bahan 


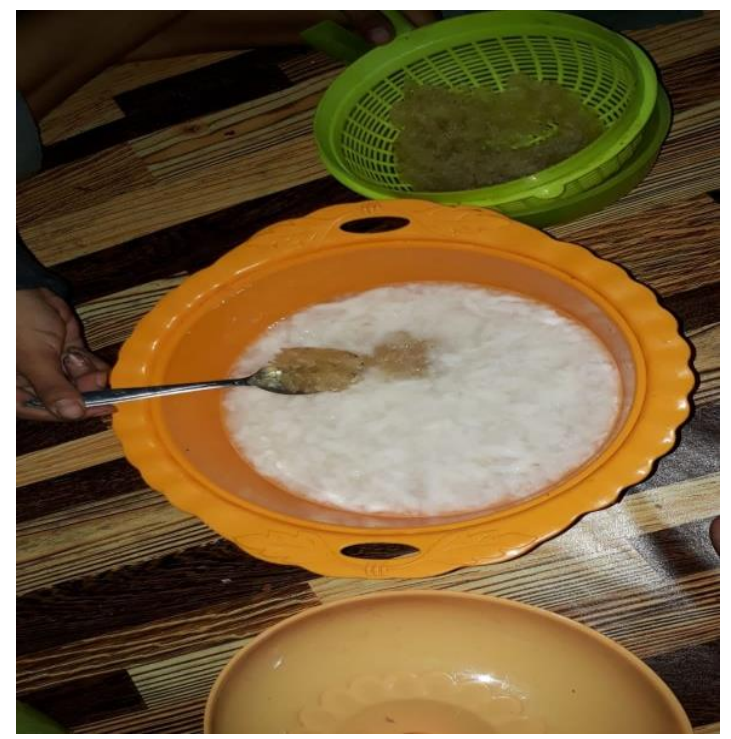

Gambar 6. Pencampuran Kelapa Muda dan Rumput Laut

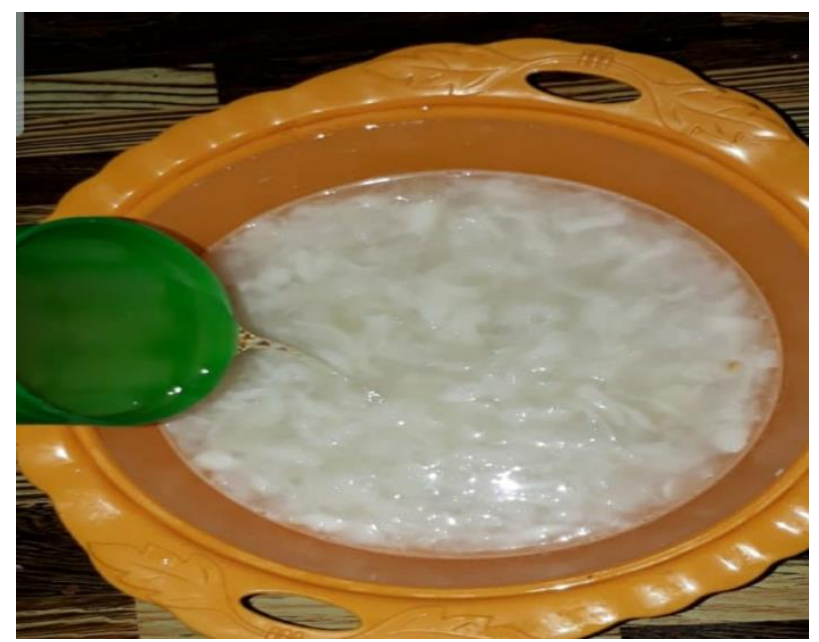

Gambar 7. Penambahan Air Gula 


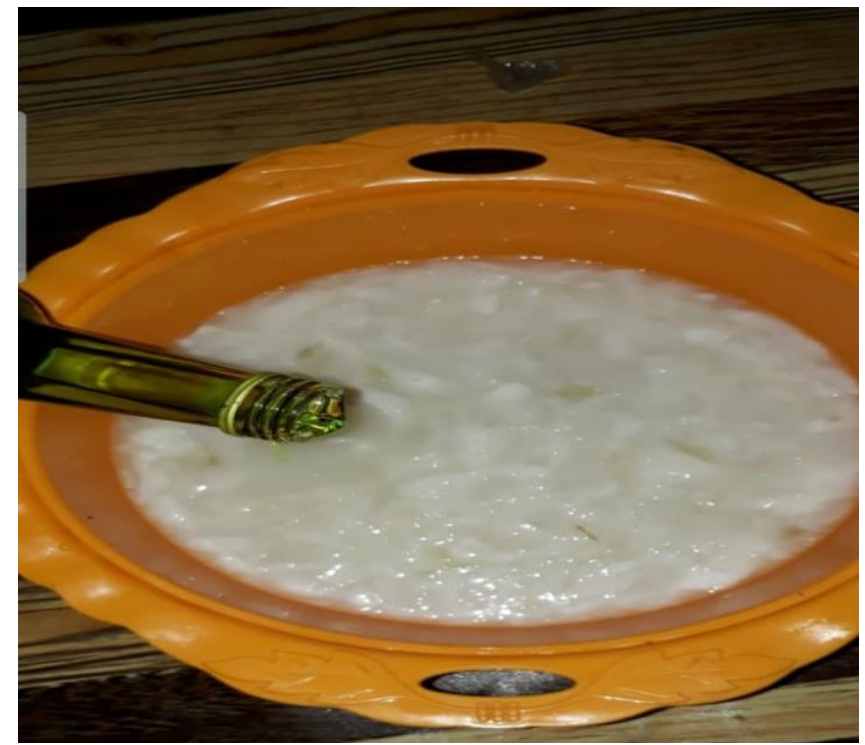

Gambar 8. Penambahan Sirup Pandan

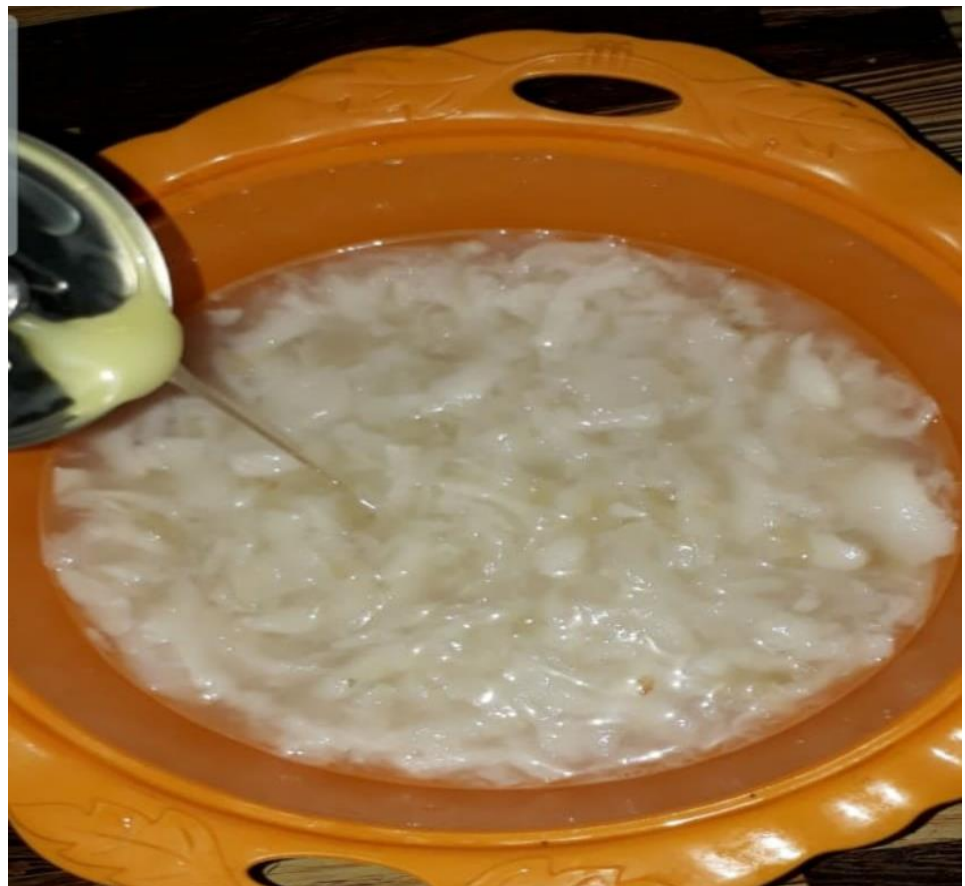

Gambar 9. Penambahan Susu Kental Manis 


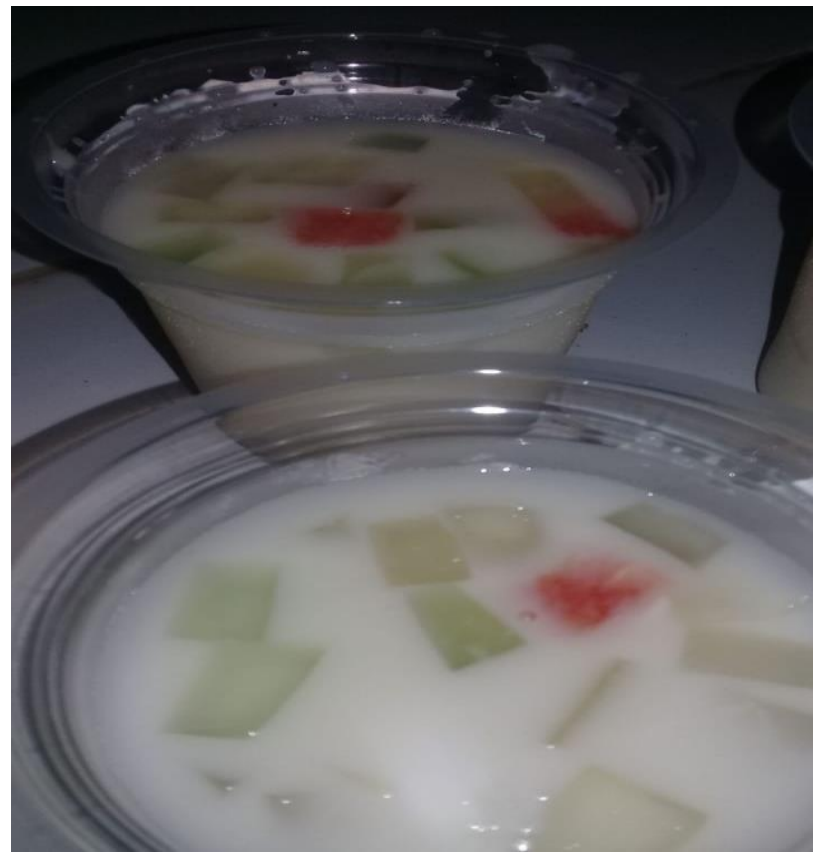

Gambar 10. Hasil Akhir

\section{E. Kesimpulan}

Kegiatan ini sangat memberi manfaat bagi masyarakat pesisir, masyarakat lebih memahami bagaimana menjadikan potensi lokal yang ada seperti Rumput Laut dapat di olah menjadi macam-macam produk yang bernilai ekonomis tinggi, salah satunya yang sudah di praktekkan oleh masyarakat yakni Es Sarang Rumput Laut. Selain produk tersebut masih banyak yang dapat dikembangkan oleh masyarakat pesisir di Desa Langkomu seperti keripik rumput laut, kerupuk rumput laut, Brownies Rumput Laut dan sebagainya. Harapan kami, generasi muda masyarakat pesisir yang merupakan penerus harus ikut serta dalam pengelolaan, pemanfaatan serta penciptaaan produk baru berbasis potensi lokal seperti Rumput Laut. Untuk mendukung hal tersebut maka kegiatan seperti ini hendaklah selalu dilakukan baik itu dalam bentuk seminar, pelatihan, penyuluhan, sosialisasi dan sebagainya, agar masyarakat mendapatkan penyegaran secara terus menerus.

\section{DAFTAR PUSTAKA}

Badan Pusat Statistik Kabupaten Buton, 2018.Kabupaten Buton Tengah Dalam Angka, Buton Tengah Regency in Figures. Katalog/catalog: 1102001.7414, ISSN : 2622-4461, BPS Kabupaten Buton: UD Syahid

Buton Tengah: Negeri Seribu Gua, Selayang Pandang, Sejarah, dan Potensi Daerah, 2015. Pemerintah Kabupaten Buton Tengah: LPPM Unhas. 
Imam, "Studi Tentang Pemberdayaan Masyarakat Petani Rumput Laut di Kelurahan Pantai Amal Kecamatan tarakan Timur Kota Tarakan”. E journal Ilmu Pemerintahan, 4(1), 2016 : 64-77 ISSN-2458.

LODM Mustari, Antasalam Ajo, Azelia Monica A, Hardin. (2019). Penyuluhan Laboratorum Lapangan Budidaya Terong Dan Cabe di Kelurahan Bandar Batauga Kecamatan Batauga Kabupaten Butonselatan. Jurnal Pengabdian Kepada Masyarakat MEMBANGUN NEGERI, 3(2), 36-47.

Muh. Askal Basir, Hardin, C. N. (2018). Pemberdayaan Perempuan Pesisir Dalam Pengelolaan Ikan Asap di Kabupaten Buton Utara. Jurnal Pengabdian Kepada Masyarakat MEMBANGUN NEGERI, 2(2), 94-102. 